\title{
A construção de identidade e a busca de legitimidade no discurso político presidencial
}

\author{
Zilda Gaspar Oliveira de Aquino ${ }^{1}$ \\ Renata Palumbo
}

\begin{abstract}
The objective of this work is to provide understanding on how the construction of identity and legitimacy takes place in the political presidential discourse, specifically in Getúlio Vargas's will letter, aimed at the Brazilian people. Focus is placed on the linguistic-discursive elements that make reference to the identity of the political leader. The analysis takes into account the agentive verbs in discourse because they are believed to play a significant role in the process of identity and legitimacy construction from the argumentative point of view. The works by Charaudeau (2009), Chilton (2004), Hall (2001), Perelman and Olbrechts-Tyteca (1996[1958]), and Franchi (1975) constitute the basis of the theoretical discussion that was carried out.
\end{abstract}

Keywords: political discourse, identity, legitimacy, argumentation, discursive strategies.

Resumo: A proposta deste trabalho é conhecer de que modo ocorre a construção da identidade e da legitimidade no discurso político presidencial, voltando-se, especificamente, ao exame da Carta Testamento de Getúlio Vargas, dirigida ao povo brasileiro. O recorte recai sobre os elementos linguístico-discursivos que fazem referência à identidade do líder político. As análises levam em conta os verbos agentivos presentes nesse discurso, por se entender que cumprem papel significativo no processo de construção da identidade e da legitimidade do ponto de vista argumentativo. As pesquisas de Charaudeau (2009), Chilton (2004), Hall (2001), Perelman e OlbrechtsTyteca (1996[1958]), Franchi (1975) constituem a base da discussão teórica empreendida.

Palavras-chave: discurso político, identidade, legitimidade, argumentação, estratégias discursivas.

Introdução

Estudos a respeito da identidade social (Cooley, 1902, Mead, 1934, Hall, 2001) indicam-nos que as concepções acerca desse tema devem-se às noções de sujeito discutidas desde o Iluminismo até os dias atuais (Hall, 2001). Tal fato decorre do modo de se entender o homem e seu lugar no mundo que leva ou à ideia de constituições fixas de identidades ou a de traços identitários socialmente delineados e flexíveis.

Quando se tem em vista que uma pessoa já nasce com uma identidade, o conceito volta-se para a essência do ser, o qual se insere em um mundo social estabilizado. Trata-

1 USP. 
se, portanto, de um sujeito individualizado e centrado, constituído por características que o moldam a partir de um quadro de referência estável em toda sua existência. Pensar por esse viés faz-nos crer em um mundo fragmentado no instante em que se localizam comportamentos variados, advindos de contratos de comunicação distintos, socialmente desenvolvidos, realizados por sujeitos que percorrem campos diversos de atuação humana.

Assim é que a ideia de individualidade do Iluminismo deixa lacunas para que se discuta acerca da relação intrínseca entre o comportamento do homem e a sociedade na qual ele vive. Nesse sentido, Hall (2001, p.2) afirma que:

[...] como nosso mundo pós-moderno, nós somos também 'pós' relativamente a qualquer concepção essencialista ou fixa de identidade - algo que, desde o Iluminismo, se supõe definir o próprio núcleo ou essência de nosso ser e fundamentar nossa existência como sujeitos humanos.

Mais do que pensarmos em um sujeito sociológico, tal como o entendiam os estudiosos dessa concepção (Cooley (1902), Mead (1934)), para quem o interior do ser e o exterior do mundo cultural unificavam-se, de modo a torná-lo previsível, temos que as identidades são delineadas pelas especificidades das interações, em um processo inesgotável de ajustamento social; isto se faz de tal modo que a construção das identidades conduza a certos deslocamentos ou mesmo contradições em relação àquilo que se espera de dados sujeitos em momentos específicos da vida, distanciando-os daquilo que se entende por sua essência.

Nessa acepção, se direcionarmos o olhar para o ocupante de um cargo político de maior representatividade, como o é o de presidente de uma nação, é usual que este crie/ busque criar uma identidade que, entre outras coisas, assegure sua permanência no poder, nesse dito inesgotável ajustamento ao social.

\section{Construção de identidade sociodiscursiva}

No caso do ex-presidente Getúlio Vargas, que esteve por duas vezes à frente da nação como presidente (de 1930 a 1945 e de 1951 a 1954), o percurso de construção de identidade apresenta-se de modo complexo e, a depender do viés de observação, contraditório. As ações políticas, sociais, discursivas que levaram à construção da identidade de um sujeito forte e fortalecido pelo apoio popular desvela-se pela instalação do contraditório, qual seja, o ato representado por seu suicídio que se constitui no deslocamento de que tratamos no parágrafo anterior. Por outro lado, a Carta Testamento, parece-nos, busca resgatar a identidade de presidente populista, de homem forte que morre pelo povo, pelo bem do povo, o que o legitima e busca tornar coerente seu ato de suicídio.

Cabe destacar, em consonância com Fairclough (2013), o caráter transformador das práticas discursivas na sociedade no que diz respeito ao seu papel orientador de conceitos e de ações sobre situações, pessoas etc., uma vez que o mundo pode ser significado várias vezes quando se torna objeto de discurso. Por essa razão, temos que a noção de uso da língua como atividade de representar a realidade dá espaço à de construí-la de maneira particular, a fazer que atitudes discursivas influam diretamente nos relacionamentos humanos e, portanto, na constituição de identidades sociodiscursivas.

A Carta Testamento de Getúlio Vargas, nesse sentido, corresponde a um exemplar com inúmeras marcas de construção de uma realidade (Getúlio ressalta à 1.1: forças e interesses contra o povo coordenaram-se novamente sobre mim) que se legitima pelo papel máximo 
do sujeito de representante da nação e que revela recorrência, pela presença dos elementos linguísticos que iniciam essa Carta: Mais uma vez e, logo a seguir, novamente (1.1).

Dessa forma, ao selecionarmos o termo 'construção', partimos do pressuposto de que a identidade não consiste de algo fixo e acabado. Por ser produto das relações sociais e objeto de discurso, ela é passível de transformações e de ajustes em interações diversas de épocas distintas, nas quais entidades constituem-se por valores e crenças a que recorrem os sujeitos em busca de uma consciência de si. Perceber-se implica constituir o lugar do outro de quem nos distanciamos, pois é necessário o estabelecimento de diferenças para que haja singularidade. É nesse sentido, a partir do conceito de princípio de alteridade, que Charaudeau (2009, p.01) nos diz que "É somente ao perceber o outro como diferente, que pode nascer, no sujeito, sua consciência identitária".

Getúlio Vargas cria sua identidade, nessa Carta, a partir da construção do que se pode dizer diverso/diferente do outro grupo (a UDN e seus partidários), de seus adversários. Mostra-se, então, defensor da nação e do povo, a partir da estratégia de trazer à lembrança seus feitos - considerados por ele - heroicos (1.8: ...fiz-me chefe de uma revolução $e$ venci...) (e 1.9... instaurei o regime de liberdade social...), além disso, deteve leis contra o país e o povo (1.11 ...A lei de lucros extraordinários foi detida...), e criou as que seriam favoráveis, pois fez a Justiça da revisão do salário mínimo (1.12), buscou a potencialização das nossas riquezas através da Petrobrás (l.13). Para o grupo adversário, resta a outra possibilidade de identidade que ele cria e que corresponde à do anti-herói, apresentado paralelamente, o que fortalece o contraste entre as ações positivas (Vargas) e negativas (os OUTROS, os adversários): revoltados contra o regime de garantia do trabalho (1.11), desencadearam ódios (1.12), onda de agitação que se avoluma (l.14), Eletrobrás obstaculada até o desespero (1.14), Não querem que o trabalhador seja livre. Não querem que o povo seja independente (1.15).

Além de se instituir por meio de diferenças, a identidade é construída à medida que semelhanças são reconhecidas, fazendo que sujeitos cheguem a certa cumplicidade, ou mesmo alcancem uma noção de pertencimento - de motivações, de atitudes, de posicionamentos - desencadeando um processo duplo: de atração por quem está engajado a determinadas ideias etc. e de rejeição por quem não está (Charaudeau, 2009). A Carta Testamento é exemplar nesse sentido.

A consequência de se ter consciência desses lugares (in)comuns corresponde à possibilidade de um sentimento de incompletude, de não acabamento, ao mesmo tempo em que se desperta para a ameaça, a competitividade. É por tal razão que a disputa entre identidades revela-se como elemento constitutivo de nossa sociedade, sobretudo no campo político, em que os posicionamentos opostos são frequentes. Nesse sentido, convencer os interlocutores de que um é melhor que outro, em uma busca constante por legitimidade, torna-se essencial para a argumentação política.

Nesse viés, ao nos voltarmos para a identidade sociodiscursiva, é preciso também levar em consideração as regras que permeiam os espaços sociais e que determinam o tomar da palavra e as construções identitárias. Sabemos que não há circunstâncias de uso da linguagem que não sejam interpeladas pelas relações de poder, as quais orientam quanto a: quem pode dizer e para quem diz, quais são os modos de se usar a linguagem, quais identidades são aceitas em certos momentos da vida social (Wodak, 2012). Pode-se dizer que as identidades correspondem a uma gama de produtos socioculturais que, para existirem, precisam de legitimação, dada tanto pela filiação biológica e pelas leis que a determinam, quanto pela filiação institucional ou mesmo pelo voto dos cidadãos, assim como ocorre no campo da política. 
A esse respeito, Charaudeau (2009, p.3) observa:

[...] a legitimidade depende de normas institucionais, que regem cada domínio da prática social e que atribuem funções, lugares e papéis aos que são investidos através de tais normas.

É assim que o olhar sobre a Carta Testamento de Getúlio Vargas pode desvelar, pelos elementos linguístico-discursivos, associados a procedimentos teórico-metodológicos, aquilo que o analista busca - marcas que podem conduzir à legitimidade, a partir de um discurso atribuído a quem ocupava o cargo máximo de representação no Brasil. Getúlio Vargas fala de um lugar que o legitima, no desempenho de um papel pleno de legitimidade, para aqueles a quem ele tinha a certeza de que o reconheceriam e nele acreditariam e que o colocaram no poder, como ele ressalta: (1.9 a 10) Voltei ao governo nos braços do povo.

Seguindo nessa direção, Fairclough (2013) afirma que significar o mundo a partir de um viés pode ser uma prática alicerçada por grupos dominantes ou hegemônicos, principalmente quando se têm em vista os campos político, midiático e educacional. Isso ocorre porque há um poder para fazer - ou mesmo um poder sobre e um por detrás de - por parte de alguém que cria um efeito de subordinação, isto é, um dominante tende a agir sobre os demais que lhe são subordinados, de maneira a conduzir olhares específicos a respeito de certos recortes do mundo.

A Carta Testamento, em seu texto pleno, traz elementos linguísticos indicativos dessa direção em que Getúlio recorta do mundo ações (lutar/ resistir/ suportar/ esquecer/renunciar/defender) que podem ajudar a significar sua ação final (oferecer a vida), a qual é dada como necessária, como se observa no excerto (1.21-25), nos elementos linguísticos em destaque:

(01)

Tenho lutado mês a mês, dia a dia, hora a hora, resistindo a uma pressão constante, incessante, tudo suportando em silêncio, tudo esquecendo, renunciando a mim mesmo, para defender o povo que agora se queda desamparado. Nada mais vos posso dar a não ser meu sangue. Se as aves de rapina querem o sangue de alguém, querem continuar sugando o povo brasileiro, eu ofereço em holocausto a minha vida.

No caso da legitimação de certas identidades, tal como a de um chefe de Estado, pode-se dizer que discursos institucionais dão subsídios para que se formem e reformem quadros de referências. Assim é que o papel social de um chefe de Estado cria certas expectativas quanto ao seu perfil identitário. Mesmo que seja inquestionável que se esperem desse líder, de modo geral, atitudes pelas quais se garanta a moralidade política, cada qual imprimirá em seus discursos particularidades a partir das quais se revele seu caráter singular diante dos OUTROS.

É possível que se localizem pistas linguísticas de um líder autoritário, de um presidente pai da nação ou pai dos pobres, de um chefe guerreiro etc. Na carta testamento de Getúlio Vargas, revela-se o presidente capaz de se sacrificar pelo povo de modo extremo, dando-lhe seu sangue, alternativa única (nada mais vos posso dar a não ser o meu sangue (1.23) que justifica sua ação, criando uma identidade de entrega da vida pelo povo e não, por exemplo, uma identidade de fracasso, de fuga de uma dada situação.

Ainda, o discurso da Carta Testamento deixa marcas que permitem observar um presidente que busca construir uma identidade não de quem entrega o poder ao oponente, mas de alguém que o transfere para a nação brasileira. O povo será, pois, a resistência ao grupo 
que assumir o poder, tendo Getúlio como o representante máximo, sagrado, sua bandeira de luta, seu guia presente em suas consciências (cf 1.28 a 30):

(02)

Meu sacrifício nos manterá unidos e meu nome será a vossa bandeira de luta. Cada gota de meu sangue será uma chama imortal na vossa consciência e manterá a vibração sagrada para a resistência.

Assim, por se tratar de uma resposta a uma expectativa social, Getúlio ganha traços identitários relacionados a um líder lutador que é capaz de se sacrificar, oferecer seu sangue em prol do povo brasileiro. Podemos dizer que segmentos dessa ordem levam-nos a uma concepção determinada acerca da construção de identidade: os sujeitos, em seus discursos, refratam (leem-se de modo próprio) identidades pré-existentes e dão um acabamento no e pelo discurso por meio da apresentação de traços identitários correspondentes ao EU e aos OUTROS. O uso dos pronomes meu e vossa, recorrentes nesse segmento, de modo exemplar, entrelaçam-se pelo nós que encaminha para a comunhão que se busca.

Além do mais, examinar identidades discursivas implica levar em conta as vozes contrárias ou alinhadas, a partir das quais se têm marcados o EU e os OUTROS. Desse modo, pode-se dizer que a pluralidade de vozes enunciadas no discurso, já discutida por Bakhtin (2003 [1979]), cumpre papel significativo nas constituições de identidades sociodiscursivas, tendo em vista que, nesse jogo de regulação, assumem-se posicionamentos de alinhamento ou repulsa e atribuem-se valorizações acerca de si e dos OUTROS. A contraposição a dadas vozes dá, pois, indícios de traços identitários do EU que enuncia. Assim também ocorre quando a polifonia revela cumplicidade e aceitação de certas condutas, em que determinados valores são retransmitidos ao enunciador.

Nesse sentido, a ideia de sacrifício de Getúlio Vargas estabelece uma linha contínua com o discurso bíblico, a permitir que se crie uma justificativa pautada na identidade de uma figura religiosa de autoridade, tendo em vista a possibilidade de que o auditório de seu discurso caracterize-se por se constituir de pessoas que, em sua maioria, aceitem os valores cristãos, como os que se localizam nos enunciados da Carta aqui destacados: ofereço em holocausto a minha vida (1.25) suportar em silêncio, minha alma sofrendo (1.27), meu sacrificio, chama imortal, vibração sagrada, perdão (1.28-30) me liberto para a vida eterna (1.32).

Tal procedimento alinha-se aos pressupostos de Charaudeau (2009), para quem a identidade discursiva é construída também pela manipulação dos imaginários sociodiscursivos, e com os de Wodak (2012), quando se refere ao fato de a identidade no e pelo discurso ser co-construída, produzida e reproduzida, podendo se manifestar simbolicamente, individual e coletivamente, nacional e internacionalmente.

Os traços identitários examinados no discurso de Getúlio Vargas consistem de procedimentos que reforçam a ideia de haver um entrelace entre identidades sociais e identidades discursivas, a permitir que uma adira à outra, não de maneira circunscrita, mas sim fluida e submetida à necessidade de uma justificativa ao público e ao próprio modo de o sujeito entender seu papel social em ocasião da produção discursiva. Entendemos que se jogue com identidades sociais já legitimadas - a de chefe de Estado, a de líder religioso atribuindo-lhes diferenças e semelhanças na tentativa de orientar raciocínios (sua morte é dada como necessária/Ele representa energia para a luta/força para a reação) e apresentar evidências (o que ele fez de bom vs. o que os outros fizerem de ruim) por meio dos quais se constitua uma justificativa plausível em relação à decisão de suicídio enunciada, que se distancia do comportamento esperado, sobretudo, de um presidente da República. Tal 
construção discursiva de identidade pode ser considerada um caminho, entre tantos, da argumentação política, em busca, sempre, de legitimidade.

\section{Os caminhos da argumentação política}

Compartilhamos com Chilton (2004) a posição segundo a qual a política constitui uma luta pelo poder. Há sempre a possibilidade, em toda sociedade, de se localizar uma relação de forças entre grupos que querem manter seu poder/manter-se no poder e os que lhes são contrários e resistem àqueles. Nesse viés, a disputa que se encerra na vida pública revela-se como discursiva e abarca encaminhamentos diversos de identidades, em razão de o alcance do poder estar diretamente ligado às imagens de si, orientadas pelos modos de dizer. A esfera política, pois, consiste de um espaço de persuasão por excelência, e a construção de identidade de políticos não pode ser entendida sem se levar em conta seu caráter argumentativo.

Pode-se afirmar também que o discurso político presidencial, sobretudo, constrói identidades dialógicas, se levarmos em conta que há um entrelace entre o singular e o coletivo, já que fala também em nome de toda a nação, e entre o singular e um terceiro, um portador de ideias (Charaudeau, 2009). Nesse processo dialógico da linguagem política, a construção de identidades volta-se para um alinhamento de imagens, constituído, minimamente, pelo político e o povo, pelo político e um sujeito singular ideológico (portador). Caso haja identificação por parte do interlocutor, a argumentação fortalece-se, amparando-se no reconhecimento e na credibilidade. Nesse sentido, se um político constrói uma identidade de si como presidente-pai, concomitantemente, criam-se uma identidade de povo-filho e de nação-família. Em contrapartida, no campo político, aos OUTROS restam as identidades desalinhadas, que comprometem a moralidade.

Seguindo nessa direção, o discurso de Getúlio Vargas, na Carta sob análise, atestou a existência de grupos contrários logo nas linhas iniciais e isto dá a orientação que ele quis e precisou argumentar para assegurar uma imagem legítima de chefe da nação mesmo cometendo suicídio. No encaminhamento argumentativo do discurso, apresentou-se um grupo que está contra seu poder, na verdade, contra o povo e é reincidente (mais uma vez... novamente (1.1-2)

Ainda é com embasamento nas discussões de Chilton (2004) que entendemos haver outro viés no que concerne à política, em que ela pode ser entendida como cooperação e, assim, grupos políticos se unem para a resolução de interesses maiores (por ex. financeiros, de liberdade, de direitos). Nessa acepção, Getúlio busca também fazer política inclusive por meio de sua Carta Testamento, a partir da aliança que quer/propõe, mas com o povo (cf exemplo (2)) e numa entrega total (1.36 a 37):

(03)

Eu vos dei a minha vida. Agora ofereço a minha morte.

Charaudeau (2008, p.83), quanto ao discurso político, salienta que a ação de defesa ou ataque pode apoiar-se sobre:

(...) o valor das idéias ao defender a legitimidade de uma causa moral (a solidariedade); o valor do programa e dos meios usados para atingi-lo (pragmatismo, realismo, eficácia); o valor dos homens e das mulheres que atuam na política, sua competência, sua experiência e seu saber-fazer. 
Getúlio valoriza suas ideias, suas ações e seu programa de governo, trazendo à lembrança o que fez (revisão de salário mínimo, defesa de nossas riquezas, como petróleo e café), mostrando seu valor na atuação política, sua experiência e, por outro lado, apresentando as contestações de quem quer derrubá-lo do poder (ódio, onda de agitação, obstáculo, cf 1.12 a 14). Nesse jogo estratégico, legitima sua causa moral e busca a solidariedade do povo para o ato que irá praticar - desistir da vida em prol do povo. Observa-se essa estratégia argumentativa nas partes destacadas:

(04)

Contra a Justiça da revisão do salário-mínimo se desencadearam os ódios. Quis criar a liberdade nacional na potencialização das nossas riquezas através da Petrobrás, mal começa esta a funcionar, a onda de agitação se avoluma. A Eletrobrás foi obstaculada até o desespero.

Lembramos, ainda, com Perelman e Olbrechts-Tyteca (1996[1958], p. 238), o que entendemos ser também pertinente à análise do documento em questão:

Uma das técnicas essenciais da argumentação quase lógica é a identificação de diversos elementos que são o objeto de discurso. Todo uso de conceitos, toda a aplicação de uma classificação, todo recurso à indução implica uma redução de certos elementos ao que neles há de idêntico ou de intercambiável; mas só qualificaremos essa redução de quase-lógica [...] quando ela dá ou pode dar azo a uma justificação argumentativa.

Assim a concepção de justiça de Getúlio faz-se a partir de elementos intercambiáveis, pois que todos os atos positivos que praticou em seu governo em prol do povo são destacados, e a posição negativa das forças contrárias é salientada. Cria-se a justificação argumentativa, pode-se dizer, fortíssima quando presente no discurso político.

A discussão a que procedemos até então permite destacar que a orientação argumentativa conduz à construção da identidade de Getúlio Vargas via Carta Testamento. A complexidade do discurso é tal que, dependendo de como o recortamos, muitas direções podem ser localizadas as quais, entretanto, acabam por convergir, fortalecendo o que se quer com esse discurso, no caso da análise aqui empreendida, a construção de uma identidade política e a busca de legitimidade. Esta legitimidade assenta-se no papel social que o líder desempenha e é reconhecido. A esse respeito, destacamos de Charaudeau (2009, p.314): "A identidade social da instância política se define através de um princípio de legitimidade, o qual se fundamenta em soberania”.

Como mencionado na seção anterior, entendemos que a construção de identidades sociodiscursivas está alicerçada por instâncias de poder. Na vida política, ainda em consonância com Charaudeau (2005), a identidade resulta de um reconhecimento, dado pela sociedade em função de alguns valores e crenças, a partir do qual se tem autoridade para falar e atuar. Seguindo nessa direção, o autor assevera que é possível legitimar alguém em decorrência de um valor supremo (divino), de um mandato (social) e de um saber. Nessa acepção, entende-se que o discurso de Getúlio é encaminhado de maneira a articular os três tipos de valores, na medida em que o mantado já lhe é conferido, a divindade é reproduzida na imagem de um político o qual se sacrifica em nome do povo, ao mesmo tempo em que se imprime o saber na apresentação de seu desempenho no cargo assumido, tal como pode-se examinar nas formulações "fiz-me chefe de uma revolução e venci. Iniciei 
o trabalho de libertação e instaurei o regime de liberdade social" (cf. linhas 8-9). Assim é que, ao assumir valores legitimados, fortalece-se a identidade construída.

Ainda é importante ressaltar que, se levarmos em conta a posição de Charaudeau (2009, p.316) no que diz respeito a atos e agentes, poderemos compreender um pouco mais o que se apresenta na Carta de Getúlio. Aquele estudioso assevera que "[...] A reação do ato sobre o agente é capaz de modificar constantemente a nossa concepção da pessoa, em se tratando de atos novos que lhe atribuímos ou de atos antigos aos quais nos referimos.". Getúlio Vargas, ao buscar a morte pelas próprias mãos, cometeu um ato novo que o povo não esperava e que poderia modificar sua identidade constituída a partir de ações anteriores; corria o risco, assim, de passar de Presidente forte, líder populista a um político frágil, fracassado. A Carta Testamento cumpre um importante papel de busca de resgate do que dele se construíra em termos de identidade a partir de ações praticadas e é na formulação dos enunciados que podemos localizar elementos linguísticos que conduzem a um processo de significação por meio de marcas lexicais denotativas de ação/agente e que correspondem aos agentivos, aqui focalizados como verbos de ação.

\subsection{Os verbos agentivos e seu papel argumentativo na construção de identidade}

A concepção de verbos agentivos na língua pode ser tomada de uma classificação Semântica, como foi entendida por Fillmore (1971), ao observar que as relações semânticas originavam-se nos verbos e referiu-se ao papel das cenas, indicando-as como decisivas na escolha e na compreensão das expressões linguísticas. Além disso, perpassam-se posições de sintaticistas como Chafe (1970), Anderson (1971), Franchi (1975)², que salientou a questão dos papéis temáticos no tratamento desses verbos, até chegar-se aos estudos do discurso com Moura, Vereza e Espíndola (2013) entre outros. Esse percurso interessanos sobremaneira, pois corresponde à discussão do verbo como elemento linguístico de extrema importância para o significado da proposição que leva em conta não questões simplesmente sintáticas, mas também semânticas, pragmáticas, ressaltando a importância do contexto para a compreensão do discurso. Um discurso, no caso da Carta Testamento, que apresenta marcas estratégicas de persuasão que orientam para mais de uma direção argumentativa, conforme entendemos.

Certos verbos agentivos apenas indicam a ação, pois o resultado desta não está implicado na semântica do verbo. Exemplos de seleções verbais dessa ordem, a partir das quais se indica a intenção, mas não o desdobramento dos fatos, são: perseguir, procurar, etc. (Moura, Vereza e Espíndola, 2013). De modo geral, pode-se dizer que alguns verbos agentivos indicam tanto a ação em si quanto seu resultado, de maneira a desencadear dois eventos distintos. Casos como esses ocorrem em ocasiões nas quais verbos dão condições de se estabelecerem certas associações e de chegarem ao estado final do acontecimento, que consiste do produto da ação verbal apresentada.

Essas estudiosas citadas estabelecem relação entre contexto e efeitos de sentido dos verbos agentivos e afirmam que nem sempre é possível considerar as implicações decorrentes de determinados verbos, em razão, por exemplo, da polissemia existente em alguns deles. Tendo como pressuposto a necessidade de se considerar por escopo o discurso ao se examinarem efeitos de sentido da seleção verbal, é possível que detectemos pistas linguísticas as quais nos levem a preencher lacunas deixadas por alguns verbos e a privilegiar uma orientação de sentido.

2 Os trabalhos desses estudiosos originaram importantes pesquisas recentes no Brasil, dentre as quais destacamos as de Borba (1996), Cançado (2000), Rocha (2003), Ignácio (2007) que trataram de retomar a questão dos verbos de modo geral e que seguem referenciados em nosso trabalho. 
O caráter argumentativo de tais verbos deve-se à força pragmática de sua seleção, por conta de se apresentarem ações-processo que podem ser relacionados aos agentes enunciados, a suscitar juízos de valor no auditório em questão, ou mesmo, conduzir efeitos de sentido quanto aos desdobramentos dos fatos narrados. À medida que consideramos as condições de produção implicadas na argumentação política, temos ainda que a seleção de verbos agentivos cumpre, na organização discursiva, um papel de orientação dupla, em razão de encaminhar tanto para a construção identitária quanto para o olhar de uma dada situação social que o locutor/enunciador recorta.

Cabe lembrar, ainda, que é no tecido discursivo, apoiado em um dado momento sócio-histórico e inserido em um campo de atuação humana, que se realizam construções dinâmicas de sentido sobre o que se fala. Nessa direção, as identidades discursivas, vistas como objetos de discurso, revelam-se por meio do jogo de relações entre informações velhas e novas (as ações anteriores de Getúlio Vargas no governo, o que estão fazendo novamente contra ele, o que ele fará), ativadas cotextual e contextualmente, amparadas por ideologias de diversas ordens e recriadas em especificas situações sociais. Assim é que entendemos o papel argumentativo dos verbos agentivos, uma vez que se voltam, concomitantemente, para os agentes do discurso e para os participantes da interação, recebendo destes julgamentos diversos conforme o entorno no qual estejam inseridos.

Dessa discussão, instauramos o percurso da observação dos verbos agentivos na construção dos enunciados como elemento dominante, centralizador, numa relação direta com seus argumentos. Esses verbos, ao indicarem ações determinadas que se relacionam a argumentos específicos ${ }^{3}$, permitem detectar o processamento de um discurso que pode levar o interlocutor (no caso, destinatários da Carta Testamento) a agir numa direção determinada - como o queria Getúlio Vargas. É possível, assim, localizar o papel temático exercido pelo argumento (agente) na relação que se apresenta. Pode-se, ainda, detectar uma rede temática que leva à construção da identidade do locutor/enunciador e do interlocutor/enunciatário, numa via dupla, em que, ao se construir uma dada identidade (quem Getúlio Vargas quer mostrar ser/como quer ser visto), a depender do papel social do locutor, acaba por se construir a identidade que se quer do interlocutor (seja em termos do povo - que lutem; seja em termos dos OUTROS - inimigos), em um processo dialógico, tal como já mencionamos. Desse modo, retomamos a posição de Cançado (2000) e a ampliamos em termos da observação da complexidade que se instaura a partir da seleção dos verbos agentivos em determinado discurso.

Observando-se o segmento (05), referente às linhas de 5 a 6 , é possível detectar uma formulação que encaminha à construção de um presidente defensor da população brasileira, ao mesmo tempo que revela um povo frágil, indefeso, humilde. Nessa direção, encaminha-se também a ideia de existirem forças contrárias que agem para que os brasileiros não tenham mais alguém forte do lado deles, no caso, Getúlio Vargas. O verbo "defender", portanto, ativa imagens específicas tanto de quem o pratica quanto de quem é afetado pela ação. Quando interage com outros, esse verbo colabora na composição de uma rede temática, na qual se vai constituindo uma cena discursiva correspondente a uma situação de conflitos de forças de grupo, na qual o presidente se situa junto ao povo.

3 Borba (1996) destaca que a seleção e ordenação de verbos agentivos pode levar ao estabelecimento de relações de causação e afetação. Esta posição parece-nos extremamente significativa para os estudos do discurso no que se refere à construção de identidade e, por isso, merece ser investigada. 
Precisam sufocar a minha voz e impedir a minha ação, para que eu não continue a defender como sempre defendi o povo e principalmente os humildes.

Assim, entendemos que as identidades sociodiscursivas delineiam-se, entre outras possibilidades, por meio das seleções lexicais que se fazem em contextos determinados e estrategicamente.

O locutor, então, conta com o fato de que seu interlocutor reconheça e compartilhe essas cenas/ esse contexto que podem ser encaminhados a partir dos verbos e das relações semânticas que nele se originam. Reafirmamos, desse modo, a importância da relação sintático-semântico-pragmática na determinação de estudos discursivos. A identificação dos verbos agentivos (tomada de uma classificação Semântica) e dos papéis temáticos (correspondentes ao papel ou função exercida pelo locutor, conforme Franchi (1975)), passíveis de serem localizados na formulação dos enunciados, permite constatar, entre outros, o encadeamento para a construção de identidade.

$\mathrm{Na}$ Carta Testamento, logo às linhas iniciais, os verbos de ação coordenar-se e desencadear-se podem ser entendidos pelo viés da ação contrária ao povo que se reflete sobre ele - Getúlio - que luta pelo povo; assim, desde o início de seu discurso dá uma orientação no sentido de que aquilo que ele fez, foi feito em prol do povo. Busca apresentar o OUTRO como inimigo e coloca-o em descrédito, dada a repetição (mais uma vez), a continuidade (novamente) das ações negativas que lhes atribui (linhas de1a 2):

Mais uma vez, as forças e os interesses contra o povo coordenaram-se novamente e se desencadeiam sobre mim.

Em especial, os verbos agentivos cumprem outro papel de orientação dupla, ao encaminharem tanto a construção identitária quanto a tese que se deseja defender. O caráter argumentativo de tais verbos deve-se, então, à seleção feita pelo locutor a partir de uma dada direção/orientação que ele quer impor ao evento, revelado por seu discurso, como se pode observar no segmento das linhas 4 a 6 , em que insultar é pior que acusar e caluniar é uma ação pior que combater. O OUTRO tira-lhe o direito garantido, pela Constituição, a qualquer cidadão (não me dão o direito de defesa) e ainda o sufocam e impedem - verbos agentivos que têm um cunho negativo e que levam à construção de uma identidade negativa do outro, a partir de suas ações que revelam uma finalidade: barrar a ação contínua de defesa de Getúlio pelo povo e pelos humildes (para que eu não continue a defender, como sempre defendi).

(07)

Não me acusam, me insultam; não me combatem, caluniam e não me dão o direito de defesa. Precisam sufocar a minha voz e impedir a minha ação, para que eu não continue $a$ defender como sempre defendi o povo e principalmente os humildes.

$\mathrm{Na}$ sequência da Carta Testamento, localizam-se verbos agentivos que encaminham à construção de uma identidade extremamente forte, de um político de resultados positivos; dentre eles, destacam-se: fiz e venci, iniciei e instaurei. O OUTRO surge como propulsor da ação negativa dele - em lugar de enunciar "renunciei", formula Tive de renunciar. Entretanto, a ação indicada pela presença do verbo agentivo Voltei denota não somente a força de seu retorno ao governo, mas vai muito além, ao associar ao verbo de ação ao 
modo (nos braços do povo), o que imprime um caráter de reconhecimento e de ação popular. Isto dá uma orientação argumentativa ao discurso de tal maneira que logo mais lhe permitirá mostrar que sempre (ele e o povo) estiveram juntos e que isto justificará sua ação, seu sacrifício por eles, conforme atesta o segmento (08), às linhas de 7 a 10:

(08)

Depois de decênios de domínio e espoliação dos grupos econômicos e financeiros internacionais, fiz-me chefe de uma revolução e venci. Iniciei o trabalho de libertação e instaurei o regime de liberdade social. Tive que renunciar. Voltei ao governo nos braços do povo.

Ao atribuir ao OUTRO ações negativas, segue defendendo sua tese de que não foi um fraco, antes agiu pelo bem do povo. Tese e construção de identidade entrelaçam-se na tessitura desse discurso.

Não se pode deixar de correlacionar o que até aqui discutimos sobre a importância dos verbos agentivos quanto a seu caráter argumentativo com a posição de Perelman e Olbrechts-Tyteca (1996[1958], p. 282-283) no que se refere à argumentação pelo sacrifício:

$\mathrm{Na}$ argumentação pelo sacrifício, este [o orador] deve medir o valor atribuído àquilo por que se faz o sacrifício. $\mathrm{O}$ argumento quase-lógico do sacrifício pode ser aplicado também a todo o campo das relações de meio com fim, sendo o meio um sacrifício, um esforço, um dispêndio, um sofrimento.

Os verbos agentivos selecionados e em destaque das linhas 21 a 25 levam a essa orientação - argumentação pelo sacrifício - como se observa a seguir pelos elementos linguísticos (tenho lutado, resistindo, suportando, renunciando, posso dar, ofereço).

(09)

Tenho lutado mês a mês, dia a dia, hora a hora, resistindo a uma pressão constante, incessante, tudo suportando em silêncio, tudo esquecendo, renunciando a mim mesmo, para defender o povo que agora se queda desamparado. Nada mais vos posso dar a não ser meu sangue. Se as aves de rapina querem o sangue de alguém, querem continuar sugando o povo brasileiro, eu ofereço em holocausto a minha vida. Escolho este meio de estar sempre convosco.

Se retormarmos, por fim, a posição de Cançado (2000, p.303) e a associarmos aos verbos agentivos, temos que:

(...) a estruturação conceitual dos eventos (da "realidade") e a estruturação lingüística de sua representação interagem de uma maneira complexa. Projetada sobre a estrutura sintática, dependendo de condições restritivas do léxico, morfologia e sintaxe, a representação conceitual adquire uma face linguística: essa face reflete, por um lado, modos específicos de estruturação da realidade, enquanto sequências de eventos espaço-temporalmente ordenadas (...)

Acrescentamos a essa discussão o fato de que a representação conceitual evidencia-se também a partir de uma face discursiva que reflete a construção de identidade(s).

\section{Considerações finais}

A Carta Testamento constitui um exemplar em que as identidades discursivas estabeleceram-se a partir de um jogo de regulação entre o EU e os outros, e as semelhanças e 


\section{Conexão Letras}

diferenças foram apresentadas de maneira a colaborar com a argumentação no discurso, para justificar a necessidade do suicídio do líder populista Getúlio Vargas. Determinadas estratégias de construção de identidades discursivas foram selecionadas e inter-relacionadas, tendo em vista a qualificação da imagem pública do presidente, sua legitimidade e a adesão a seus atos.

Sabemos que as identidades discursivas de políticos constituem-se a partir da relação de força existente entre eles. Nesse sentido, promover avaliações atraindo o que é positivo para si, e negativo paro o outro, pode configurar uma orientação argumentativa a partir da qual o sujeito alcance a adesão pretendida. A seleção e a ordenação de verbos agentivos podem ser auxiliares na promoção do encaminhamento avaliativo do discurso, em especial do discurso político presente na Carta Testamento, que já em seu exórdio ativou traços de identidades: EU - líder político defensor dos pobres e dos humildes, libertador e vencedor vs os OUTROS: políticos autoritários e caluniadores.

Vargas constrói, pelo discurso, a identidade de si e dos OUTROS ao mesmo tempo, desde o exórdio, e esse mecanismo pode levar ao fortalecimento da argumentação, na tentativa de busca de adesão à ação que se quer realizar e que, no caso de Getúlio, correspondeu à ação de suicidar-se.

O que apresentamos como discussão corresponde a uma das possibilidades de recorte e análise de um discurso em termos da seleção de verbos agentivos, da orientação argumentativa que promovem e da construção de identidade a que podem encaminhar. É pertinente, entretanto, ressaltar a posição de Perelman e Olbrechts-Tyteca (1996[1958], p. 337), para quem: [...] a construção da pessoa jamais está terminada, nem se quer à sua morte.

\section{Referências}

ANDERSON, J.M. The grammar of case: towards a localistic theory. Cambridge/UK: Cambridge University Press. 1971.

BAKHTIN, M. M. Os gêneros do discurso (1952-3). In: Estética da criação verbal. São Paulo: Martins Fontes. 2003 [1979]: 261-306.

BASTOS, P.P.Z.; FONSECA, P.C.D. (Org.). A era Vargas - desenvolvimento, economia e sociedade. São Paulo: Ed. UNESP, 2011.

BORBA, F. S. Uma gramática de valências para o português. São Paulo: Ática, 1996. CANÇADO, M.. O Papel do Léxico em uma Teoria dos Papéis Temáticos. DELTA, vol.16 no.2. 2000. p. 297-321.

COOLEY, C. H. Human Nature and Social Order. New York: Scribner's, 1902. CHAFE, W.L. Meaning and the structure of language. Chicago: University of Chicago Press. 1970.

CHARAUDEAU, P. Discurso Político. Trad. Fabiana Komesu e Dilson F. Cruz. São Paulo: Contexto, 2008.

. Identidade Social e identidade discursiva, o fundamento da competência comunicacional. In: PIETROLUONGO, M. (org.). O trabalho da tradução. Rio de janeiro: Contra Capa, 2009. p.309-326.

CHILTON, P. A. Analysing political discourse. United Kingdon: Routledge, 2004. FAIRCLOUGH, I; FAIRCLOUGH, N. Argument, deliberation, dialectic and the nature of the political. A ACD perspective. Political Studies Review, Political Studies Association, v.11, n.3, 2013. p.336-344. 
FILLMORE, Ch.J. Some problems for case grammar. In: 22 ${ }^{\text {nd }}$ Annual Roundtable Meeting on Linguistics and Language Studies. Richard J. O'Brien (ed.). Washington D.C.: Georgetown University Press, 1971. p.35-56.

FRANCHI, C. Hipóteses para uma Teoria Funcional da Linguagem. Tese de doutorado. Campinas: IEL/UNICAMP. 1975.

HALL, S. A Identidade Cultural na Pós-Modernidade. 6.ed. Rio de Janeiro: DP\&A, 2001.

IGNÁCIO, S. E.. Ação, agentividade e causatividade em estruturas oracionais de ação-processo. Estudos Lingüísticos XXXVI(1), janeiro-abril, 2007. p. 126 / 132.

MEAD, G. H.. Mind, self, and society. Chicago: University of Chicago Press, 1934. MOURA, H.; VEREZA, S.; SPINDOLA, L.. Metáfora e contexto: entre o estável e o instável. Interdisciplinar • Edição Especial ABRALIN/SE, Ano VI, v.17, jan./jun. 2013. p.177-199.

PERELMAN, C.; OLBRECHTS-TYTECA, L. Tratado da Argumentação. A Nova Retórica. Trad. Maria Ermentina Galvão. São Paulo: Martins Fontes, 1996 [1958].

ROCHA, S.A.D.O. Os movimentos semânticos e as nuanças que emergem da linguagem na mídia impressa. Tese de Doutorado. Universidade Federal de Santa Catarina. 2003.

WODAK, R. Language, power and identity. Language Teaching, v.45, n.2, 2011. p. 215-233.

Anexo

\section{CARTA-TESTAMENTO}

Mais uma vez, as forças e os interesses contra o povo coordenaram-se novamente e se desencadeiam sobre mim.

Não me acusam, me insultam; não me combatem, caluniam e não me dão o direito de defesa. Precisam sufocar a minha voz e impedir a minha ação, para que eu não continue a defender como sempre defendi, o povo e principalmente os humildes. Sigo o destino que me é imposto. Depois de decênios de domínio e espoliação dos grupos econômicos e financeiros internacionais, fiz-me chefe de uma revolução e venci. Iniciei o trabalho de libertação e instaurei o regime de liberdade social. Tive que renunciar. Voltei ao governo nos braços do povo. A campanha subterrânea dos grupos internacionais aliou-se à dos grupos nacionais revoltados contra o regime de garantia do trabalho. A lei de lucros extraordinários foi detida no Congresso. Contra a Justiça da revisão do salário-mínimo se desencadearam os ódios. Quis criar a liberdade nacional na potencialização das nossas riquezas através da Petrobrás, mal começa esta a funcionar, a onda de agitação se avoluma. A Eletrobrás foi obstaculada até o desespero. Não querem que o trabalhador seja livre. Não querem que o povo seja independente. Assumi o Governo dentro da espiral inflacionária que destruía os valores do trabalho. Os lucros das empresas estrangeiras alcançavam até 500\% ao ano. Nas declarações de valores do que importávamos existiam fraudes constatadas de mais de 100 milhões de dólares por ano. Veio a crise do café, valorizou-se o nosso principal produto. Tentamos defender seu preço e a resposta foiuma violenta pressão sobre a nossa economia a ponto de sermos obrigados a ceder. Tenho lutado mês a mês, dia a dia, hora a hora, resistindo a uma pressão constante, in- 


\section{Conexão Letras}

cessante, tudo suportando em silêncio, tudo esquecendo, renunciando a mim mesmo, para defender o povo que agora se queda desamparado. Nada mais vos posso dar a não ser meu sangue. Se as aves de rapina querem o sangue de alguém, querem continuar sugando o povo brasileiro, eu ofereço em holocausto a minha vida. Escolho este meio de estar sempre convosco. Quando vos humilharem sentireis minha alma sofrendo ao vosso lado. Quando a fome bater à vossa porta, sentireis em vosso peito a energia para a luta por vós e vossos filhos. Quando vos vilipendiarem, sentireis no meu pensamento a força para a reação. Meu sacrifício nos manterá unidos e meu nome será a vossa bandeira de luta. Cada gota de meu sangue será uma chama imortal na vossa consciência e manterá a vibração sagrada para a resistência. Ao ódio respondo com o perdão. E aos que pensam que me derrotaram respondo com a minha vitória. Era escravo do povo e hoje me liberto para a vida eterna. Mas esse povo de quem fui escravo não mais será escravo de ninguém. Meu sacrifício ficará para sempre em sua alma e meu sangue terá o preço do seu resgate.

Lutei contra a espoliação do Brasil. Lutei contra a espoliação do povo. Tenho lutado de peito aberto. $\mathrm{O}$ ódio, as infâmias, a calúnia, não abateram meu ânimo. Eu vos dei a minha vida. Agora ofereço a minha morte. Nada receio. Serenamente dou o primeiro passo no caminho da eternidade e saio da vida para entrar na história. 